\title{
Pluripotent Stem Cells for Cardiac Regeneration - Current Status, Challenges, and Future Perspectives -
}

\author{
Yuji Shiba, MD, PhD
}

\begin{abstract}
Loss of myocardium permanently impairs cardiac function because the adult mammalian heart has limited regenerative capacity. Strategies to regenerate injured heart tissue include the transplantation of multiple types of stem cells. Among them, pluripotent stem cells (PSCs) are a promising option because of their unlimited self-renewal and unequivocal cardiomyogenic ability. To date, advances in stem cell biology allow generation of relatively homogeneous human PSC-derived cardiomyocytes (CMs). In this regard, preclinical studies of PSC-CM transplantation in rodents and larger animal models have provided convincing proof-of-concept results, triggering clinical studies in multiple countries. However, a few important uncertainties are yet to be addressed, warranting further investigation before clinical implementation of this novel therapy. An overview of the potential of stem cell therapy to provide new CMs for cardiac regeneration is presented.
\end{abstract}

Key Words: Cardiomyocytes; Heart failure; Pluripotent stem cells; Regeneration

$\mathbf{H}$ eart failure (HF) is a devastating condition caused by many cardiovascular diseases and affects more than 26 million individuals worldwide. ${ }^{1}$ In Japan, the prevalence of HF has been steadily increasing, and the number of patients is projected to reach 1.3 million by 2030 as the population ages. ${ }^{2}$

Following cardiac injury, cardiomyocytes (CMs) undergo necrosis or apoptosis. The surviving CMs have minimal proliferative capacity, resulting in non-contractile fibrous tissue formation. Although current pharmaceutical and non-pharmaceutical therapies can delay the progression of this condition, there is no fundamental treatment for $\mathrm{HF}$ apart from heart transplantation, which is facing a donor heart shortage. A promising strategy to overcome this hurdle is substitution of functional CMs. This review will focus on the potential of stem cell therapy to provide new $\mathrm{CMs}$ for cardiac regeneration.

\section{Adult Stem Cells}

Several postmortem clinical studies following cardiac or bone marrow transplantation have provided evidence that CMs can be derived from bone marrow cells. Laflamme et al found the presence of $\mathrm{Y}$ chromosomes in female allograft hearts transplanted into male recipients. ${ }^{3}$ Besides, the presence of $\mathrm{Y}$ chromosome-positive CMs in female subjects who underwent sex-mismatched bone marrow transplantation has been reported. ${ }^{4}$ The existence of bone marrow-derived CMs motivated the development of adult stem cell-based strategies for cardiac repair. Preclinical and clinical studies using adult stem cells, including bone marrow-derived cells, mesenchymal stem cells, skeletal myocytes, and resident cardiac stem cells, yielded inconsistent results, ${ }^{5}$ likely because transplanted adult stem cells cannot survive long-term or transdifferentiate into CMs. ${ }^{6}$ Although the mechanism underlying adult stem cell transplantation's contribution to cardiac repair remains obscure, it may involve paracrine effects on preexisting cardiac tissues. $^{7}$

\section{Pluripotent Stem Cells (PSCs)}

Since the establishment of human embryonic stem cells (ESCs) by Thomson et al in 1998, ${ }^{8}$ researchers have utilized ESCs for heart regeneration. Human ESCs (hESCs) reportedly differentiate into $\mathrm{CMs}$, and these human ESC-derived CMs (hESC-CMs) have survived long-term following transplantation into multiple animal recipients. ${ }^{9-12}$ hESCs, as a source for regenerative medicine, have practically unlimited self-renewal capacity, which enables abundant generation of specific cellular subsets. However, as hESCs are generated from the inner cell mass of blastocysts, ethical implications limit the application of hESCs to cardiac regeneration. Besides, donor hESC-derivatives must be used for allogeneic transplantation. Following the establishment of induced pluripotent stem cells (iPSC) in mice, ${ }^{13}$ human iPSC (hiPSC) were established in 2007.14 Like hESCs, hiPSC display unlimited self-renewal capacity and the ability to differentiate into CMs..$^{15}$ Furthermore, hiPSC are free of ethical concerns because they theoretically represent autologous transplantation. Potential disadvantages of iPS cells include an increased risk of carcinogenesis

Received July 10, 2020; revised manuscript received August 30, 2020; accepted September 7, 2020; J-STAGE Advance Publication released online October 20, 2020

Department of Regenerative Science and Medicine, Institute for Biomedical Sciences, Shinshu University, Matsumoto, Japan

Mailing address: Yuji Shiba, MD, PhD, Department of Regenerative Science and Medicine, Institute for Biomedical Sciences, Shinshu University, 3-1-1 Asahi, Matsumoto 390-8621, Japan. E-mail: yshiba@shinshu-u.ac.jp

All rights are reserved to the Japanese Circulation Society. For permissions, please e-mail: cj@j-circ.or.jp

ISSN-1346-9843 
post-grafting due to genetic modifications accumulated during preparation; notably, the risk exceeds that associated with ESCs.

\section{Generation of PSC-Derived CMs}

The only method to obtain ESC-derived CMs was harvesting spontaneously beating 3D ESC aggregates, also known as embryoid bodies. Unlike mouse ESCs, spontaneous differentiation of hESCs into CMs is rare; 16 therefore, higher purity cardiac cell preparations were required to utilize hESC-CMs for clinical applications.

The initial approach to enhancing cardiac purity consisted of isolating beating CMs from cocultures of hESCs and END-2 cells. ${ }^{17}$ The purity was further enhanced by adding p38 MAP kinase inhibitor. ${ }^{18}$

The Murry group reported a guided cardiac differentiation protocol involving sequential addition of activin $\mathrm{A}$ and bone morphogenetic protein 4 (BMP4) ${ }^{10}$ to monolayer cultured hESCs in serum-free medium, which resulted in a yield of $>30 \%$ CMs 3 weeks post-induction. The purity was further enhanced using the matrix sandwich method reported by the Kamp group. ${ }^{19}$ Briefly, singularized hESCs were allowed to reach $80-90 \%$ confluence on Matrigelcoated plates and covered with fresh Matrigel-containing medium, followed by activin A/BMP4 addition.

Canonical Wnt signaling, which is required for mesoderm induction, reportedly inhibits later pre-cardiac mesoderm induction. ${ }^{20}$ Therefore, the Keller group developed a protocol involving the Wnt inhibitor dickkopf homolog 1 (DKK1) following induction with activin A/BMP4.21

The cardiac differentiation protocol has been further refined by modulating the Wnt signaling by replacing growth factors with small molecules, ${ }^{22,23}$ which allow inexpensive and reproducible generation of human CMs. ${ }^{24}$ Furthermore, most of the protocols described above, originally designed for generating hESC-CMs, were reproducible for hiPSC-CMs.

\section{Purification of PSC-Derived CMs}

Although the exact degree of purification required for successful grafting without adverse effects remains unknown, high-purity CM preparations may curtail the incidence of adverse effects. However, despite the tremendous progress in the development of cardiac differentiation protocols, the homogeneous preparation of pure $\mathrm{CMs}$ remains challenging. Nevertheless, approaches to purify CMs include conventional cell sorting techniques, using CM-specific cell-surface markers. The Keller group identified the signal-regulatory protein $\alpha$ (SIRPA) as a specific marker for human CMs. They obtained $>95 \%$ pure cardiac troponin $\mathrm{T}^{+} \mathrm{CMs}$ from the SIRPA ${ }^{+}$fraction isolated by flow cytometry. ${ }^{25}$

Another approach to purifying CMs is genetic selection. Multiple groups have established genetically modified hESCs harboring antibody resistance genes under the control of cardiac-specific genes such as $\alpha-\mathrm{MHC}^{26}$ and MLC2v. ${ }^{27}$ However, the major drawback of this approach is the potential risk of genetic modifications.

The Fukuda group established a simpler yet more effective approach based on CMs' unique metabolic properties. Tohyama et al found that glucose-depleted and lactateenriched culture conditions could purify murine and human PSC-CMs. ${ }^{28}$ They further enhanced purity to obtain $>99 \%$ pure CMs by depleting glucose and glutamine. ${ }^{29}$

\section{Engraftment of Human PSC-Derived CMs and Mechanical Benefits Following Transplantation}

Several transplantation studies of PSC-CMs have been performed using multiple animal models. Initial studies were conducted by transplanting hESC-CMs into small animal models to confirm both the engraftment of hESC$\mathrm{CMs}$ in animal hearts and the mechanical benefits posttransplantation. The Gepstein group ${ }^{30}$ transplanted undifferentiated hESCs or hESC-CMs into rat hearts. Although transplantation of undifferentiated hESCs resulted in teratoma formation in the recipient hearts, transplantation of hESC-CMs remuscularized the scar tissue and attenuated functional deterioration following cardiac injury. Laflamme et al transplanted hESC-CMs with a Matrigel-based pro-survival cocktail into a rat infarct model and observed substantial remuscularization accompanied by mechanical benefits. ${ }^{10}$ The Mummery group observed modest improvements in cardiac contractile function 4 weeks after transplantation of hESC-CMs in an acutely infarcted mouse model; however, no significant differences in contractile function between recipients of hESC-CMs and controls were found 12 weeks post-transplantation. ${ }^{31}$ Many groups have also independently demonstrated that transplantation of human PSC-CMs remuscularized injured hearts without tumor formation and produced cardiac mechanical benefits in an acute injury model. ${ }^{21}$ Given that relatively few grafted CMs survived in the aforementioned studies, mechanical benefits following CMs transplantation may be attributed not only to direct force generation produced by grafted CMs but also indirect paracrine effects, including CM proliferation enhancement, and anti-apoptosis, and anti-fibrosis effects. ${ }^{32}$ Although transplantation of hESC-CMs 4 days after ischemia-reperfusion cardiac injury reportedly exerted mechanical benefits in a rat model, ${ }^{10}$ no beneficial effects in the equivalent chronic myocardial infarction model, in which hESC-CMs were transplanted 4 weeks post-infarction, were observed. ${ }^{33}$ Similarly, in guinea pig models, our group found that grafted hESC-CMs survived in an acute cardiac cryoinjury model and were electrically integrated, leading to cardiac contractile restoration. ${ }^{11}$ However, grafted hESC-CMs in a chronic injury model showed less incidence of electrical integration with host CMs and no beneficial effects. ${ }^{34}$ It seems reasonable that a chronically injured heart with extended fibrous tissue and an enlarged left ventricle is less likely to integrate with grafted CMs and show mechanical benefits. The mechanical benefits in chronic injury models that better reflect the characteristics of end-stage HF in clinical patients should be further investigated.

\section{Electrophysiological Characteristics Following Transplantation of PSC-Derived CMs}

It has long been debated whether grafted PSC-CMs show pro- or anti-arrhythmogenic effects. Roell et al reported that the transplantation of primary murine embryonic CMs markedly decreased the incidence of induced ventricular tachycardia (VT) in cryoinjured hearts in mice, an antiarrhythmogenic effect that correlated with the expression of the gap junction protein connexin-43, but not with the restoration of mechanical function. ${ }^{35}$ Subsequently, my group reported that the transplantation of hESC-CMs decreased the incidence of induced VT in cryoinjured guinea pig hearts. ${ }^{11}$ Conversely, Chong et al reported spontaneous 
VT or accelerated idioventricular rhythm following transplantation of hESC-CMs in a non-human primate model of myocardial infarction. ${ }^{12} \mathrm{We}$ reported that allogeneic transplantation of induced PSC-CMs significantly increased the incidence of VT in a non-human primate model of myocardial infarction. ${ }^{36}$ This post-transplant VT was frequently observed between 2 and 4 weeks aftertransplantation. However, the incidence decreased gradually, and no VT was observed at 12 weeks' post-transplantation. Although some animals appeared healthy without any abnormal behavior, they showed sustained VT over $24 \mathrm{~h}$, possibly due to the relatively slower beating rate of VT. These inconsistencies in arrhythmogenesis following transplantation of PSC-CMs could be explained by differences in the size and beating rate of recipients' hearts. Because post-transplant VT in human recipients is possible, more studies are required to assess and control the risk of posttransplant VT. The Murry group ${ }^{37}$ performed electrical mapping studies to understand the basis for this arrhythmia. Although they could not identify the reentrant pathway during VT, the impulse was found to originate from the graft area. They also failed to terminate the VT by either overdrive pacing or electrical cardioversion. These findings suggest that post-transplant VT is caused by the generation of impulses from ectopic pacing rather than reentry. The Laflamme group ${ }^{38}$ recently reproduced post-transplant VT in a swine model. Although the post-transplant VT was more frequent and lethal in the pigs than in monkeys, the time course of the arrhythmia was similar. They also performed detailed electroanatomical mapping and suggested that post-transplant VT could be attributed to an automatic focal mechanism, although they could not completely exclude the possibility of a micro-reentry mechanism. PSC-CMs possibly contribute to the ectopic pacemaker ${ }^{39}$ because they show relatively immature automaticity and contain phenotypically nodal-like $\mathrm{CMs}^{40}$ Grafted CMs have been shown to mature in vivo over time. ${ }^{12,38}$ This ventricular maturation may give rise to decreased incidence of post-transplant VT at later stages. Our group transplanted hESC-CMs into rats with intact and infarcted hearts and compared the characteristics of graft $\mathrm{CMs}$ at 2, 4, and 12 weeks post-transplantation, based on a previous transplantation study, ${ }^{36}$ in which the incidence of post-transplant VT was frequent at 2 and 4 weeks post-transplantation but decreased gradually and disappeared at 12 weeks post-transplantation. In addition, the expression of MLC2a in the graft, which reflects nodal, atrial, or immature ventricular CMs, decreased gradually, whereas the expression of MLC2v, which reflects mature ventricular CMs, increased. Interestingly, although patchclamp-based electrophysiological analysis showed that approximately $10 \%$ of hESC-CMs exhibited a nodal-like action potential pattern in our cell preparation, and an equivalent fraction of nodal-like CMs survived in the grafted tissue until 4 weeks post-transplantation, the fraction of nodal-like CMs significantly decreased by 12 weeks post-transplantation. ${ }^{41}$ Although the precise mechanisms underlying the decrease of nodal-like CMs in the graft remains unclear, decreased fractions of immature and nodal-like CMs may account for the transient incidence of post-transplant VT. Further studies involving transplantation of PSC-derived matured ventricular CMs are warranted.

Another important issue regarding the electrophysiological aspect of PSC-CM grafting is whether PSC-CMs integrate with host CMs. To test the electrophysiological integration between human PSC-CMs and host CMs, rodents would not be appropriate recipient animals because of their extremely rapid heart rates as compared with humans (heart rates of mouse and rat are 600 and 400 beats/min, respectively ${ }^{42}$ ). Our group transplanted hESC-CMs expressing fluorescent $\mathrm{Ca}$ indicator GCaMP3 into guinea pig hearts, whose beating rate is approximately 200-250 beats/min. ${ }^{43}$ Intravital imaging at 4 weeks posttransplantation revealed that most of the grafted CMs had successfully coupled with host CMs. Subsequently, Chong et al and our group showed indisputable electrical integration of grafted PSC-CMs with infarcted non-human primate hearts. ${ }^{12,36}$

\section{PSC-Derived Engineered Heart Tissue (EHT) as a Cardiac Repair Tool}

The adult human heart is a complex organ with aligned myocardium connected with Purkinje fibers, stromal cells, and nerve fibers, perfused by a vascular network. Reproduction of this complexity via a simple injection of dispersed PSC-CMs is extremely unlikely. Tissue engineering approaches may be useful in overcoming this hurdle. As reviewed in detail elsewhere, ${ }^{44}$ this field has progressed quite rapidly to the stage where reproducing the complexity of cardiac tissue may be possible. Although EHT can be utilized as a platform for disease modeling and drug testing, the focus here is as a tool for cardiac repair. A common type of EHT is the hydrogel-based cell patch that has been tested in different animal models. ${ }^{45,46}$ Menasche et al $^{47}$ performed the first clinical application of hESC-derivatives for cardiac repair. They created a fibrin patch containing hESC-derived cardiac progenitor cells and transplanted it onto an infarcted heart concomitantly with coronary artery bypass grafting. They reported 6 cases of patients receiving hESC-derived cardiac progenitor cell patch transplantation. ${ }^{48}$ All patients showed symptomatic improvement except for 1 who died from unrelated comorbidities. None of them showed tumor formation or graft-related arrhythmia. Another type of EHT is the stacked cell sheet. ${ }^{49}-51$ Recently, the Sawa group launched a clinical trial of transplanting hiPSC-CM sheets into patients with ischemic HF. The advantage of EHT over direct intramuscular injection is its safety; EHT can be delivered without injection-induced needle injury or bleeding, and transplantation of EHT does not seem to induce graft-related arrhythmia. ${ }^{52}$ Another advantage of EHT is better short-term cell retention than with direct injection. ${ }^{49}$ The potential disadvantage of EHT is limited electrical integration. Electrical integration of grafted EHT has various pros ${ }^{46}$ and cons..$^{53}$ Notably, epicardial transplantation induces an inflammatory response, leading to the formation of a fibrous cap, separating the grafted EHT from the host heart,,$^{\mathbf{5 3}}$ and limiting electrical integration. Given that the cause of post-transplant VT is a graft-related electrical activity, it is reasonable that no VT will be induced by grafted EHT with limited or no electrical integration.

\section{Important Questions to Be Answered}

Perhaps the most concerning risk following transplantation of PSC-CMs is the post-transplant ventricular arrhythmia, as discussed above. Although PSC-CMs have already been transplanted in human clinical trials, several other important 


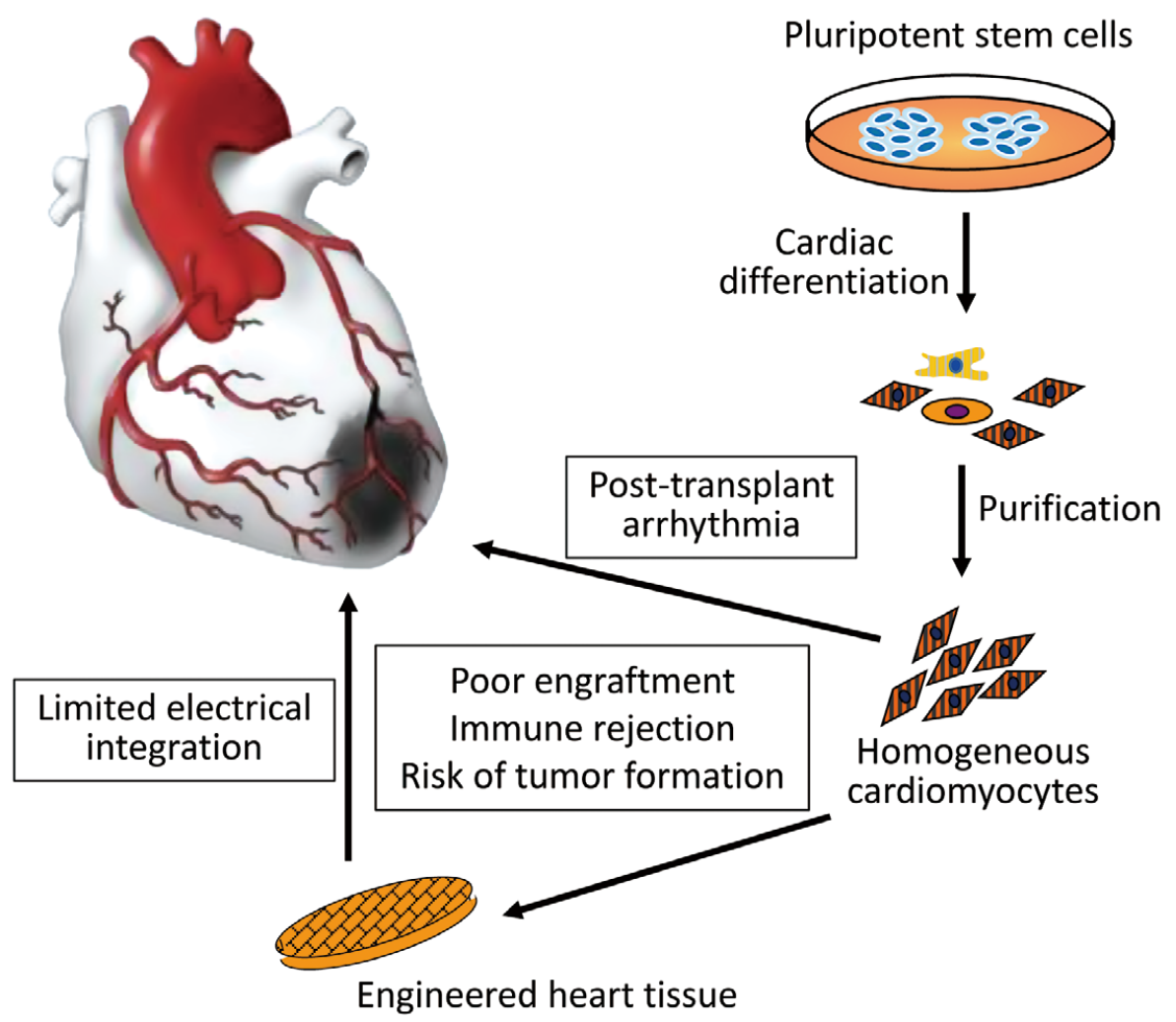

Figure. Current strategy and remaining challenges in pluripotent stem cell-based cardiac regeneration.

issues remain unresolved, as detailed next (Figure).

\section{Immature Phenotype of PSC-Derived CMs}

PSC-CMs exhibit an immature phenotype akin to fetal CMs. PSC-CMs are smaller in size, ${ }^{54}$ with shorter sarcomere length ${ }^{\mathbf{5 5}}$ without $\mathrm{T}$ tubes, ${ }^{\mathbf{5 6}}$ and express fetal isoforms of myofilament proteins, such as $\alpha$-myosin heavy chain, ${ }^{55}$ slow skeletal troponin I, ${ }^{57}$ and N2BA titin. ${ }^{58}$ PSC-CMs beat spontaneously due to higher expression of $\mathrm{HCN} 4,{ }^{59}$ with a less hyperpolarized resting membrane potential due to lower expression of the inward-rectifier potassium channel $\mathrm{K}_{\text {ir } 2.1,60}$ and slower upstroke velocity due to the fetal isoform of the $\mathrm{Na}_{v} 1.5 \alpha$-subunit of the sodium channel. ${ }^{61}$ Multiple studies showed that grafted PSC-CMs grow ${ }^{\mathbf{6 2 , 6 3}}$ and mature ${ }^{\mathbf{2}, 41,64}$ over time. Even simple, prolonged culture enhances the maturation of PSC-CMs. ${ }^{55}$ More specific ways to enhance their maturation have been reported, such as $3 \mathrm{D}$ culture, ${ }^{65}$ hormonal treatment, ${ }^{66}$ electrical stimulation, ${ }^{67}$ and physical stretch. ${ }^{68}$ However, the maturation state of CMs that is optimal for cardiac repair remains unknown. Transplantation of immature CMs would be more likely to induce post-transplant arrhythmia. However, fully mature CMs, such as adult CMs, have limited ability to proliferate, which results in insufficient remuscularization. Studies to conclusively elucidate the effect of cardiac maturation on graft size and the incidence of arrhythmia are required.

\section{Poor Engraftment}

Despite substantial efforts to enhance the survival of PSCCMs following transplantation, their engraftment and long-term survival are still critical issues. Grafted CMs may disappear through multiple plausible mechanisms, such as leakage or rapid washout, anoikis (i.e., apoptosis induced by cell detachment from the extracellular matrix), harsh environment within the host, such as inflammation and ischemia, and the host immune response. Studies focusing on methods to attenuate these mechanisms will be required to make this novel therapy viable.

\section{Immune Rejection}

The host immune response against graft tissue primarily affects the long-term survival of transplanted CMs. Most studies in this field have been performed using xenogeneic models in which human PSC-CMs are transplanted into animals. However, these studies provide limited insight regarding host-graft immune reactions in allogeneic transplantation. Theoretically, iPSCs can be used for autologous transplantation, which is the ideal solution to prevent graft immune rejection. However, autologous transplantation comes with substantial challenges from the regulatory, manufacturing, and cost perspectives. Alternatively, allogeneic transplantation using off-the-shelf, cryopreserved cell products is a viable strategy. We transplanted major histocompatibility complex (MHC)-homozygous iPSCCMs into non-human primate recipients in whom either of the MHC haplotypes was matched, and found that graft CMs survived at least 3 months under tacrolimus and methylprednisolone treatment. ${ }^{36}$ Although a similar strategy has been carried out in Japan using human iPS cells from individuals with homozygous $\mathrm{MHC},{ }^{69}$ several studies 
indicate that it still requires long-term immunosuppression. ${ }^{70,71}$ With recent advancements in gene-editing technology, immune gene-editing approaches have been proposed. ${ }^{72}$ Polymorphisms in human leukocyte antigen (HLA) class I genes essentially cause graft rejection in allogeneic transplantation. The disruption of HLA class I gene or Beta-2 microglobulin, a protein subunit required for surface expression of HLA class I, leads to activation of host natural killer (NK) cells. ${ }^{73}$ NK cell activation is physiologically inhibited by HLA class I molecule interactions. ${ }^{74}$ Based on this knowledge, several attempts have been made to generate immunocompatible universal PSCs, including HLA-E overexpressed ESCs, ${ }^{75} \mathrm{HLA}-\mathrm{C}$ retained iPSCs, ${ }^{76}$ and CD47 overexpressed iPSCs. ${ }^{77}$ These promising approaches may reduce or even terminate the need for immunosuppressant therapy; however, further studies are needed.

\section{Potential Risk of Tumor Formation}

Although ESCs and iPSCs share a risk of teratoma formation stemming from residual undifferentiated cells, there is a distinct risk associated with iPSCs because of the cellular reprogramming process. iPSCs were initially established by transduction of 4 transcription factors, OCT4, SOX2, $M Y C$, and $K L F 4$, which are also highly expressed in various types of cancer. ${ }^{78}$ Generally, the tumorigenic risk is enhanced by the increase in the number of cells delivered. It is reassuring that, in multiple large animal studies, where up to 1 billion PSC-CMs have been transplanted, tumor formation has not been detected. ${ }^{12,36-38}$ It appears that the tumorigenic risk following PSC-CM transplantation is extremely low as long as the cells are of sufficient purity. Still, the observation periods in the aforementioned large animal studies were not sufficiently long ( $<3$ months) to allow a definitive conclusion regarding long-term tumorigenesis. Longer follow-up studies in large animal models are warranted.

\section{Conclusions and Future Perspective}

To date, clinical applications of PSC-based cardiac regeneration are a reality. However, both clinical and preclinical studies to establish standard protocols, including target diseases, optimal treatment timing, cell dose, delivery method, risk management, and the immunosuppressive protocol, are pending. However, the efforts to develop this novel therapy could lead to improvements in the health condition of millions of patients worldwide.

\section{Acknowledgments}

I thank all my co-workers, especially my mentors Dr. Masafumi Takahashi and Dr. Michael A. Laflamme. This work was partly supported by JSPS KAKENHI (grant numbers 18K19539, 17H04173, and 26293182).

\section{Disclosures}

None.

\section{References}

1. Savarese G, Lund LH. Global public health burden of heart failure. Card Fail Rev 2017; 3: 7-11.

2. Okura Y, Ramadan M M, Ohno Y, Mitsuma W, Tanaka K, Ito $\mathrm{M}$, et al. Impending epidemic: Future projection of heart failure in Japan to the year 2055. Circ J 2008; 72: 489-491.

3. Laflamme MA, Myerson D, Saffitz JE, Murry CE. Evidence for cardiomyocyte repopulation by extracardiac progenitors in transplanted human hearts. Circ Res 2002; 90: 634-640

4. Deb A, Wang S, Skelding KA, Miller D, Simper D, Caplice NM. Bone marrow-derived cardiomyocytes are present in adult human heart: A study of gender-mismatched bone marrow transplantation patients. Circulation 2003; 107: 1247-1249.

5. Menasché P. Cell therapy trials for heart regeneration: Lessons learned and future directions. Nat Rev Cardiol 2018; 15: 659671.

6. Murry CE, Soonpaa MH, Reinecke H, Nakajima H, Nakajima HO, Rubart M, et al. Haematopoietic stem cells do not transdifferentiate into cardiac myocytes in myocardial infarcts. Nature 2004; 428: 664-668.

7. Eschenhagen T, Bolli R, Braun T, Field LJ, Fleischmann BK, Frisén J, et al. Cardiomyocyte regeneration: A Consensus Statement. Circulation 2017; 136: 680-686.

8. Thomson JA, Itskovitz-Eldor J, Shapiro SS, Waknitz MA, Swiergiel JJ, Marshall VS, et al. Embryonic stem cell lines derived from human blastocysts. Science 1998; 282: 1145-1147.

9. van Laake LW, Passier R, Doevendans PA, Mummery CL. Human embryonic stem cell-derived cardiomyocytes and cardiac repair in rodents. Circ Res 2008; 102: 1008-1010.

10. Laflamme MA, Chen KY, Naumova AV, Muskheli V, Fugate JA, Dupras SK, et al. Cardiomyocytes derived from human embryonic stem cells in pro-survival factors enhance function of infarcted rat hearts. Nat Biotechnol 2007; 25: 1015-1024.

11. Shiba Y, Fernandes S, Zhu WZ, Filice D, Muskheli V, Kim J, et al. Human ES-cell-derived cardiomyocytes electrically couple and suppress arrhythmias in injured hearts. Nature 2012; 489: $322-325$.

12. Chong JJ, Yang X, Don CW, Minami E, Liu YW, Weyers JJ, et al. Human embryonic-stem-cell-derived cardiomyocytes regenerate non-human primate hearts. Nature 2014; 510: 273-277.

13. Takahashi K, Yamanaka S. Induction of pluripotent stem cells from mouse embryonic and adult fibroblast cultures by defined factors. Cell 2006; 126: 663-676.

14. Takahashi K, Tanabe K, Ohnuki M, Narita M, Ichisaka T, Tomoda K, et al. Induction of pluripotent stem cells from adult human fibroblasts by defined factors. Cell 2007; 131: 861-872.

15. Zhang J, Wilson GF, Soerens AG, Koonce CH, Yu J, Palecek $\mathrm{SP}$, et al. Functional cardiomyocytes derived from human induced pluripotent stem cells. Circ Res 2009; 104: e30-e41.

16. Kehat I, Kenyagin-Karsenti D, Snir M, Segev H, Amit M, Gepstein A, et al. Human embryonic stem cells can differentiate into myocytes with structural and functional properties of cardiomyocytes. J Clin Invest 2001; 108: 407-414.

17. Mummery C, Ward-van Oostwaard D, Doevendans P, Spijker $\mathrm{R}$, van den Brink S, Hassink R, et al. Differentiation of human embryonic stem cells to cardiomyocytes: Role of coculture with visceral endoderm-like cells. Circulation 2003; 107: 2733-2740.

18. Graichen R, Xu X, Braam SR, Balakrishnan T, Norfiza S, Sieh $\mathrm{S}$, et al. Enhanced cardiomyogenesis of human embryonic stem cells by a small molecular inhibitor of p38 MAPK. Differentiation 2008; 76: $357-370$.

19. Zhang J, Klos M, Wilson GF, Herman AM, Lian X, Raval KK, et al. Extracellular matrix promotes highly efficient cardiac differentiation of human pluripotent stem cells: The matrix sandwich method. Circ Res 2012; 111: 1125-1136.

20. Ueno S, Weidinger G, Osugi T, Kohn AD, Golob JL, Pabon L, et al. Biphasic role for Wnt/beta-catenin signaling in cardiac specification in zebrafish and embryonic stem cells. Proc Natl Acad Sci USA 2007; 104: 9685-9690.

21. Yang L, Soonpaa MH, Adler ED, Roepke TK, Kattman SJ, Kennedy M, et al. Human cardiovascular progenitor cells develop from a KDR+ embryonic-stem-cell-derived population. Nature 2008; 453: 524-528.

22. Minami I, Yamada K, Otsuji TG, Yamamoto T, Shen Y, Otsuka $\mathrm{S}$, et al. A small molecule that promotes cardiac differentiation of human pluripotent stem cells under defined, cytokine- and xeno-free conditions. Cell Rep 2012; 2: $1448-1460$.

23. Zhao M, Tang Y, Zhou Y, Zhang J. Deciphering role of Wnt signalling in cardiac mesoderm and cardiomyocyte differentiation from human iPSCs: Four-dimensional control of Wnt pathway for hiPSC-CMs differentiation. Sci Rep 2019; 9: 19389.

24. Lian X, Hsiao C, Wilson G, Zhu K, Hazeltine LB, Azarin SM, et al. Robust cardiomyocyte differentiation from human pluripotent stem cells via temporal modulation of canonical Wnt signaling. Proc Natl Acad Sci USA 2012; 109: E1848-E1857.

25. Dubois NC, Craft AM, Sharma P, Elliott DA, Stanley EG, Elefanty AG, et al. SIRPA is a specific cell-surface marker for isolating cardiomyocytes derived from human pluripotent stem 
cells. Nat Biotechnol 2011; 29: 1011-1018.

26. Anderson D, Self T, Mellor IR, Goh G, Hill SJ, Denning C. Transgenic enrichment of cardiomyocytes from human embryonic stem cells. Mol Ther 2007; 15: 2027-2036.

27. Huber I, Itzhaki I, Caspi O, Arbel G, Tzukerman M, Gepstein A, et al. Identification and selection of cardiomyocytes during human embryonic stem cell differentiation. Faseb J 2007; 21: $2551-2563$.

28. Tohyama S, Hattori F, Sano M, Hishiki T, Nagahata Y, Matsuura T, et al. Distinct metabolic flow enables large-scale purification of mouse and human pluripotent stem cell-derived cardiomyocytes. Cell Stem Cell 2013; 12: 127-137.

29. Tohyama S, Fujita J, Hishiki T, Matsuura T, Hattori F, Ohno $\mathrm{R}$, et al. Glutamine oxidation is indispensable for survival of human pluripotent stem cells. Cell Metab 2016; 23: 663-674.

30. Caspi O, Huber I, Kehat I, Habib M, Arbel G, Gepstein A, et al. Transplantation of human embryonic stem cell-derived cardiomyocytes improves myocardial performance in infarcted rat hearts. J Am Coll Cardiol 2007; 50: 1884-1893.

31. van Laake LW, Passier R, Monshouwer-Kloots J, Verkleij AJ, Lips DJ, Freund C, et al. Human embryonic stem cell-derived cardiomyocytes survive and mature in the mouse heart and transiently improve function after myocardial infarction. Stem Cell Res 2007; 1: 9-24.

32. Kervadec A, Bellamy V, El Harane N, Arakélian L, Vanneaux V, Cacciapuoti I, et al. Cardiovascular progenitor-derived extracellular vesicles recapitulate the beneficial effects of their parent cells in the treatment of chronic heart failure. $J$ Heart Lung Transplant 2016; 35: 795-807.

33. Fernandes S, Naumova AV, Zhu WZ, Laflamme MA, Gold J, Murry CE. Human embryonic stem cell-derived cardiomyocytes engraft but do not alter cardiac remodeling after chronic infarction in rats. J Mol Cell Cardiol 2010; 49: 941 -949.

34. Shiba Y, Filice D, Fernandes S, Minami E, Dupras SK, Biber BV, et al. Electrical integration of human embryonic stem cell-derived cardiomyocytes in a guinea pig chronic infarct model. $J$ Cardiovasc Pharmacol Ther 2014; 19: 368-381.

35. Roell W, Lewalter T, Sasse P, Tallini YN, Choi BR, Breitbach $\mathrm{M}$, et al. Engraftment of connexin 43-expressing cells prevents post-infarct arrhythmia. Nature 2007; 450: 819-824.

36. Shiba Y, Gomibuchi T, Seto T, Wada Y, Ichimura H, Tanaka Y, et al. Allogeneic transplantation of iPS cell-derived cardiomyocytes regenerates primate hearts. Nature 2016; 538: 388-391.

37. Liu YW, Chen B, Yang X, Fugate JA, Kalucki FA, FutakuchiTsuchida A, et al. Human embryonic stem cell-derived cardiomyocytes restore function in infarcted hearts of non-human primates. Nat Biotechnol 2018; 36: 597-605.

38. Romagnuolo R, Masoudpour H, Porta-Sanchez A, Qiang B, Barry J, Laskary A, et al. Human embryonic stem cell-derived cardiomyocytes regenerate the infarcted pig heart but induce ventricular tachyarrhythmias. Stem Cell Reports 2019; 12: $967-$ 981

39. Kehat I, Khimovich L, Caspi O, Gepstein A, Shofti R, Arbel G, et al. Electromechanical integration of cardiomyocytes derived from human embryonic stem cells. Nat Biotechnol 2004; 22: $1282-1289$.

40. Protze SI, Liu J, Nussinovitch U, Ohana L, Backx PH, Gepstein $\mathrm{L}$, et al. Sinoatrial node cardiomyocytes derived from human pluripotent cells function as a biological pacemaker. Nat Biotechnol 2017; 35: 56-68.

41. Ichimura H, Kadota S, Kashihara T, Yamada M, Ito K, Kobayashi $\mathrm{H}$, et al. Increased predominance of the matured ventricular subtype in embryonic stem cell-derived cardiomyocytes in vivo. Sci Rep 2020; 10: 11883.

42. Swoap SJ, Overton JM, Garber G. Effect of ambient temperature on cardiovascular parameters in rats and mice: A comparative approach. Am J Physiol Regul Integr Comp Physiol 2004; 287: R391-R396.

43. Shiotani M, Harada T, Abe J, Hamada Y, Horii I. Methodological validation of an existing telemetry system for QT evaluation in conscious guinea pigs. J Pharmacol Toxicol Methods 2007; 55: $27-34$.

44. Weinberger F, Mannhardt I, Eschenhagen T. Engineering cardiac muscle tissue: A maturating field of research. Circ Res 2017; 120: $1487-1500$.

45. Riegler J, Tiburcy M, Ebert A, Tzatzalos E, Raaz U, Abilez OJ, et al. Human engineered heart muscles engraft and survive long term in a rodent myocardial infarction model. Circ Res 2015; 117: $720-730$.

46. Weinberger F, Breckwoldt K, Pecha S, Kelly A, Geertz B,
Starbatty J, et al. Cardiac repair in guinea pigs with human engineered heart tissue from induced pluripotent stem cells. Sci Transl Med 2016; 8: 363ra148.

47. Menasche P, Vanneaux V, Hagege A, Bel A, Cholley B, Cacciapuoti I, et al. Human embryonic stem cell-derived cardiac progenitors for severe heart failure treatment: First clinical case report. Eur Heart J 2015; 36: 2011-2017.

48. Menasché P, Vanneaux V, Hagège A, Bel A, Cholley B, Parouchev A, et al. Transplantation of human embryonic stem cell-derived cardiovascular progenitors for severe ischemic left ventricular dysfunction. J Am Coll Cardiol 2018; 71: 429-438.

49. Sekine H, Shimizu T, Dobashi I, Matsuura K, Hagiwara N, Takahashi M, et al. Cardiac cell sheet transplantation improves damaged heart function via superior cell survival in comparison with dissociated cell injection. Tissue Eng Part A 2011; 17: 2973 2980.

50. Kawamura M, Miyagawa S, Miki K, Saito A, Fukushima S, Higuchi T, et al. Feasibility, safety, and therapeutic efficacy of human induced pluripotent stem cell-derived cardiomyocyte sheets in a porcine ischemic cardiomyopathy model. Circulation 2012; 126: S29-S37.

51. Masumoto H, Ikuno T, Takeda M, Fukushima H, Marui A, Katayama S, et al. Human iPS cell-engineered cardiac tissue sheets with cardiomyocytes and vascular cells for cardiac regeneration. Sci Rep 2014; 4: 6716.

52. Pecha S, Yorgan K, Röhl M, Geertz B, Hansen A, Weinberger $F$, et al. Human iPS cell-derived engineered heart tissue does not affect ventricular arrhythmias in a guinea pig cryo-injury model. Sci Rep 2019; 9: 9831 .

53. Gerbin KA, Yang X, Murry CE, Coulombe KL. Enhanced electrical integration of engineered human myocardium via intramyocardial versus epicardial delivery in infarcted rat hearts. PLoS One 2015; 10: e0131446.

54. Snir M, Kehat I, Gepstein A, Coleman R, Itskovitz-Eldor J, Livne E, et al. Assessment of the ultrastructural and proliferative properties of human embryonic stem cell-derived cardiomyocytes. Am J Physiol Heart Circ Physiol 2003; 285: H2355-H2363.

55. Lundy SD, Zhu WZ, Regnier M, Laflamme MA. Structural and functional maturation of cardiomyocytes derived from human pluripotent stem cells. Stem Cells Dev 2013; 22: 1991-2002.

56. Lieu DK, Liu J, Siu CW, McNerney GP, Tse HF, Abu-Khalil A, et al. Absence of transverse tubules contributes to non-uniform $\mathrm{Ca}(2+)$ wavefronts in mouse and human embryonic stem cellderived cardiomyocytes. Stem Cells Dev 2009; 18: 1493-1500.

57. Sasse S, Brand NJ, Kyprianou P, Dhoot GK, Wade R, Arai M, et al. Troponin I gene expression during human cardiac development and in end-stage heart failure. Circ Res 1993; 72: 932-938.

58. Hinson JT, Chopra A, Nafissi N, Polacheck WJ, Benson CC, Swist S, et al. HEART DISEASE: Titin mutations in iPS cells define sarcomere insufficiency as a cause of dilated cardiomyopathy. Science 2015; 349: 982-986.

59. Carmeliet E. Pacemaking in cardiac tissue: From IK2 to a coupled-clock system. Physiol Rep 2019; 7: e13862.

60. Yonemizu S, Masuda K, Kurata Y, Notsu T, Higashi Y, Fukumura K, et al. Inhibitory effects of class I antiarrhythmic agents on $\mathrm{Na}(+)$ and $\mathrm{Ca}(2+)$ currents of human iPS cell-derived cardiomyocytes. Regen Ther 2019; 10: 104-111.

61. Veerman CC, Mengarelli I, Lodder EM, Kosmidis G, Bellin M, Zhang M, et al. Switch from fetal to adult SCN5A isoform in human induced pluripotent stem cell-derived cardiomyocytes unmasks the cellular phenotype of a conduction disease-causing mutation. J Am Heart Assoc 2017; 6: e005135.

62. Laflamme MA, Gold J, Xu C, Hassanipour M, Rosler E, Police $\mathrm{S}$, et al. Formation of human myocardium in the rat heart from human embryonic stem cells. Am J Pathol 2005; 167: 663-671.

63. Funakoshi S, Miki K, Takaki T, Okubo C, Hatani T, Chonabayashi K, et al. Enhanced engraftment, proliferation, and therapeutic potential in heart using optimized human iPSCderived cardiomyocytes. Sci Rep 2016; 6: 19111.

64. Kadota S, Pabon L, Reinecke H, Murry CE. In vivo maturation of human induced pluripotent stem cell-derived cardiomyocytes in neonatal and adult rat hearts. Stem Cell Rep 2017; 8: 278-289.

65. Ronaldson-Bouchard K, Ma SP, Yeager K, Chen T, Song L, Sirabella D, et al. Advanced maturation of human cardiac tissue grown from pluripotent stem cells. Nature 2018; 556: 239-243.

66. Parikh SS, Blackwell DJ, Gomez-Hurtado N, Frisk M, Wang L, Kim K, et al. Thyroid and glucocorticoid hormones promote functional T-tubule development in human-induced pluripotent stem cell-derived cardiomyocytes. Circ Res 2017; 121: $1323-$ 1330 . 
67. Nunes SS, Miklas JW, Liu J, Aschar-Sobbi R, Xiao Y, Zhang B, et al. Biowire: A platform for maturation of human pluripotent stem cell-derived cardiomyocytes. Nat Methods 2013; 10: 781787.

68. Ruan JL, Tulloch NL, Razumova MV, Saiget M, Muskheli V, Pabon L, et al. Mechanical stress conditioning and electrical stimulation promote contractility and force maturation of induced pluripotent stem cell-derived human cardiac tissue. Circulation 2016; 134: 1557-1567.

69. Azuma K, Yamanaka S. Recent policies that support clinical application of induced pluripotent stem cell-based regenerative therapies. Regen Ther 2016; 4: 36-47.

70. Ichise H, Nagano S, Maeda T, Miyazaki M, Miyazaki Y, Kojima $\mathrm{H}$, et al. NK cell alloreactivity against KIR-ligandmismatched HLA-haploidentical tissue derived from HLA haplotype-homozygous iPSCs. Stem Cell Rep 2017; 9: 853-867.

71. Kawamura T, Miyagawa S, Fukushima S, Maeda A, Kashiyama N, Kawamura A, et al. Cardiomyocytes derived from MHChomozygous induced pluripotent stem cells exhibit reduced allogeneic immunogenicity in MHC-matched non-human primates. Stem Cell Rep 2016; 6: 312-320.

72. Cong L, Ran FA, Cox D, Lin S, Barretto R, Habib N, et al. Multiplex genome engineering using CRISPR/Cas systems.
Science 2013; 339: 819-823.

73. Bix M, Liao NS, Zijlstra M, Loring J, Jaenisch R, Raulet D. Rejection of class I MHC-deficient haemopoietic cells by irradiated MHC-matched mice. Nature 1991; 349: 329-331.

74. Pazmany L, Mandelboim O, Valés-Gómez M, Davis DM, Reyburn HT, Strominger JL. Protection from natural killer cell-mediated lysis by HLA-G expression on target cells. Science 1996; 274: 792-795.

75. Gornalusse GG, Hirata RK, Funk SE, Riolobos L, Lopes VS, Manske G, et al. HLA-E-expressing pluripotent stem cells escape allogeneic responses and lysis by NK cells. Nat Biotechnol 2017; 35: $765-772$.

76. Xu H, Wang B, Ono M, Kagita A, Fujii K, Sasakawa N, et al. Targeted disruption of HLA genes via CRISPR-Cas9 generates iPSCs with enhanced immune compatibility. Cell Stem Cell 2019; 24: $566-578 . e 567$.

77. Deuse T, Hu X, Gravina A, Wang D, Tediashvili G, De C, et al. Hypoimmunogenic derivatives of induced pluripotent stem cells evade immune rejection in fully immunocompetent allogeneic recipients. Nat Biotechnol 2019; 37: 252-258

78. Ben-David U, Benvenisty N. The tumorigenicity of human embryonic and induced pluripotent stem cells. Nat Rev Cancer 2011; 11: 268-277. 